\title{
Designing a national model for assessment of nursing informatics competency
}

\author{
Mehrdad Farzandipour ${ }^{1}$, Hashem Mohamadian ${ }^{2}$, Hossein Akbari ${ }^{3}$, Samira Safari ${ }^{1}$ and Reihane Sharif ${ }^{*}$ (D)
}

\begin{abstract}
Background: Due to the need for informatics competencies in the field of nursing, the present study was conducted to design a psychometric instrument to determine the qualification of informatics competencies of employed nurses in educational care centers.

Methods: The questionnaire was made by reviewing existing scientific resources and assessment tools. Two hundred nurses were selected using simple random sampling. Structural equation modeling was used using the measurement model technique and the average variance was calculated. Linear structural relations (LISREL) software was used to test the assumptions and correlations of the model.
\end{abstract}

Results: Findings showed relatively good estimation in the fit of first-order measurement model. The informatics knowledge subscale with a determining rate of 0.90 had the greatest explanatory effect among the subscales and informatics skill with a determining rate of 0.67 and basic computer skill with a determining rate of 0.60 were observed. The second-order measurement model of fitness indicators showed that the three factors can well explain the multidimensional construct of informatics competency.

Conclusions: The designed tool can be used to develop educational strategies in relation to nursing students in the field of informatics and prepare them in the rich environment of information technology, which can be helpful in training nursing instructors.

Keywords: Average variance extracted, Composite reliability, Confirmatory factor analysis, Nursing informatics competency, Assessment

\section{Background}

Health informatics is the interdisciplinary study of the design, development, adoption and application of ITbased innovations in healthcare services delivery, management and planning that covers a wide range of applied subfields including medical informatics, consumer health informatics, Bioinformatics, nursing informatics, dental informatics and public health informatics [1]. Informatics

\footnotetext{
*Correspondence: Fr.sharif@yahoo.com

${ }^{1}$ Health Information Management Research Center, Department

of Health Information Management and Technology, School of Allied Health Professions, Kashan University of Medical Sciences, Pezeshk Blvd, 5th of Qotbe Ravandi Blvd - Pardis Daneshgah, Kashan, Islamic Republic of Iran

Full list of author information is available at the end of the article
}

in these terms refers to the "computer science and study of computational systems that is broader context than information science that encompasses all aspects of the computer environment" [2]. Nursing informatics (NI), a subset of health informatics, is an established and growing specialty in the nursing field [3], which is defined as a science and practice that integrates nursing, information, and knowledge with information and communication technologies to enhance the health of people, families, and communities worldwide [4]. The HIMSS Nursing Informatics Workforce Survey (2020) showed that nursing informatics plays an important role in the development, implementation, and optimization of information systems and applications, including clinical documentation $(\mathrm{CD})$, computerized provider order 
entry (CPOE), and electronic health records (EHR) [5]. There is evidence that awareness of the nursing informatics competencies is necessary to fulfill their professional responsibilities [6].

Competence is defined as the state of being well qualified, and it means having the knowledge, skills, and ability to perform specific tasks, activities, or professions [7]; however, it also includes the concept of values, attitudes, critical thinking, and clinical decision-making [8]. Therefore, nursing informatics competencies can be defined as adequate knowledge, skills, and abilities to perform specific informatics tasks [9]. Today, to maintain public health as one of nursing education's main goals, much emphasis has been placed on evaluating and empowering nursing informatics competencies $[10,11]$. Without informatics standards and competencies, information technology would be ineffective in the healthcare setting and impose risks on patient safety.

By 1988, nurses in the International Medical Informatics Association and the National League for Nursing developed the first informatics competencies, and other studies soon followed [12, 13]. However, these identified competencies only described entry-level competencies such as computer skills for nurses, rather than the more sophisticated informatics skills needed by experienced nurses, especially informatics nurse specialists (INS). Renewed interest in informatics competencies for nurses began in the early 2000s. Staggers et al. [14-16] defined the initial standard for determining, ranking, and evaluating nursing informatics competencies. This was the first study to cover four levels of nursing, developed competencies for both entry-level and experienced INS, and examined the categories of computer skills, informatics knowledge, and informatics skills [14].

In Iran, as a developing country, the need to consider the concept of nursing informatics competencies has been emphasized in recent years. Some of the topics related to competency mainly focus on clinical competencies, such as nursing managers, nurse educators, nursing students, and nursing graduates [6]. However, extensive research in this area is limited and so far, only a few studies have been conducted concerning the concept of the nursing informatics competencies in this country. In a study (2019), the effect of a training program was examined on the nursing informatics competencies of critical care nurses in Iran based on the Nursing Informatics Competency Assessment Tool (NICAT) [17]. This tool is developed based on the need for an acute care setting and is not generalizable to all healthcare settings [18]. Therefore, due to the changes in technology and newer technologies required in nursing, more attention should be paid to the informatics competencies for the development and standardization of this concept in various aspects of the nursing profession. To that end, the present study aimed to design a psychometric instrument to qualify the informatics competencies of nurses employed in the educational health care centers.

\section{Methods}

\section{Study design, setting and participants}

This descriptive, cross-sectional study was conducted in Iran in 2018 to investigate the psychometric properties and factor structures of nursing informatics competencies. Eligible nurses with Bachelor's degrees participating in this study needed to have full-time job experience of at least 3 years in eight teaching hospitals in the country. Table 1 shows the research outline in January-October, 2018.

\section{Questionnaire development}

After a review of previous studies and evaluation of existing tools and scientific resources associated with nursing informatics competencies, the basic items of the questionnaire were extracted and then classified into three domains (computer skills, informatics knowledge, and informatics skills) based on the study conducted by Staggers et al. (2002) [14]. The questionnaire consisted of 74 items at three subscales: Basic Computer Skills (22 items), Informatics Knowledge (25 items), and Informatics Skills (27 items). It should be noted that computer skills in this study is defined as the proficiency in the use of computer hardware and software and should not be confused with computer science.

The questionnaire was reviewed in a focus group of twelve experts, including eight nursing experts holding a Master's degree or faculty members with at least five years of work experience with hospital information systems (HIS) and four information technology (IT)

Table 1 Research outline

\begin{tabular}{ll}
\hline Executive activities & Total time \\
\hline Collecting data, filling in the questionnaires, and entering the data into the software & (January-April 2018) 4 months \\
Information analysis & (May-July 2018) 3 months \\
Reviewing, concluding and writing the manuscript & (August-October 2018) 3 months \\
Total & 10 Months \\
\hline
\end{tabular}


professionals holding a Bachelor's degree with at least five years of work experience in the IT department of the hospital. Experts scored the importance of each item on a 5-point Likert scale ranging from 'strongly disagree' to 'strongly agree'. The average importance of informatics competencies items was estimated separately for each item, and then the final questionnaire was designed.

The content validity of the questionnaire was assessed by the same experts using the content validity ratio (CVR) [19] and content validity index (CVI) [20]. In CVR, experts' responses for each item were measured based on the three scales of (1) 'necessary', (2) 'helpful but not necessary', and (3) 'not necessary'. Then, according to the Lawshe table[21], items with a content validity ratio (CVR) higher than 0.56 were considered acceptable. To calculate CVI, relevance, clarity, and simplicity of all items were checked using a 4-point Likert scale, and items with CVI $>0.79$ were considered appropriate. Finally, the items were confirmed in three basic computer skills (17 items), informatics knowledge (15 items), and informatics skills (16 items) subscales. Following validity assessment, content reliability of the questionnaire was assessed using the test-retest method. Thus, a valid version of the questionnaire was administered to 20 nurses. After two weeks, the participating nurses were asked to fill out the questionnaire again. Cronbach's alpha was used to assess data reliability. Data reliability was calculated as 0.97 .

\section{Data collection}

Before conducting the research, verbal consent was obtained from all participants. They were informed that they could withdraw from the study at any time during filling out the questionnaires if they do not want to continue. All questionnaires were anonymous, and the participants were assured of the confidentiality of their information. This study was approved by the ethics committee of Kashan University of Medical Sciences (KAUMS).

\section{Study size}

The confirmatory factor analysis (CFA) designed to validate an appropriate and meaningful instrument was used to assess nursing informatics competencies. In this study, the sample comprised 200 nurses eligible for the study. According to Kline [20], in the factor analysis, the minimum sample size of 200 is defensible. Thus, the sample size of the present study was larger because, in the confirmatory factor analysis, the minimum sample size is determined based on the subscales, not the items. All samples were selected using a simple random sampling technique according to a list of nurses with a Bachelor's or higher degree and three years of work experience with
Hospital Information System (HIS) in teaching and medical hospitals.

\section{Data sources and measurement}

The questionnaire comprising two parts was distributed among nurses. The first part included demographic characteristics including age, sex, marital status, employment, level of education, work experience, familiarity with computers, frequency of computer usage, and interactions with the HIS. The second part included questions related to the subscale of informatics competencies on a scale of 48 questions.

The validity of the constructed instrument was analyzed through confirmatory factor analysis [22] using LISREL software (version 8.5). LISREL has also been used for the structural equation modeling in two parts: confirmatory factor analysis and path analysis. In order to assess the amount of fitness in the developed measurement model, confirmatory factor analysis and experimental data were used to get the chi-square index, chi-square goodness of fit index, adjusted goodness of fit index, comparative fit index, and the root mean square error of approximation (RMSEA) [23]. In this study, structural equation modeling was used with the help of measurement model, composite reliability, and construct validity (convergent and discriminant) using the maximum likelihood approach through LISREL 8.5 software to test the assumptions and correlations of the model.

Convergent validity shows the compatibility of items measuring the same construct. Three methods were evaluated to achieve convergent validity and solidarity: (a) factor loading suggested by Haire et al. [24] as the accreditation criterion for the factor loading of the numeric amount of 6.0 and above. It is noteworthy that if the amount of the factor loading of an item in conjunction with a construct is higher, the item plays a greater role in explaining the constructs. If the factor loading is less than 3.0, the role of the item is not significant, so that it will be ignored. The factor loading between 3.0 and 6.0 is considered acceptable. If it is greater than 6.0, it will be desirable. (b) Composite reliability shows the number of item reflections on the desired construct. The amount of the proposed criterion of composite reliability is 7.0, confirming that the reliability is acceptable [25]. (c) The average extracted variance is equal to or more than 0.5 $[26,27]$. In discriminant validity, the amount of difference between the items of the construct and those of other constructs was evaluated. The most common way to assess discriminant validity needs to be formed in the correlation matrix (Fornell and Larker) [28]. Therefore, the original diagonal values are the root of Average Variance Extracted (AVE) coefficients of each construct, and lower values of original diagonal are the correlation 
coefficients of each construct with other constructs. Based on the accreditation criterion, the original diameter values should be greater than the diameter.

\section{Results}

\section{Demographic characteristics}

Out of 200 questionnaires distributed, 197 were completed. The response rate was $98.5 \%$. About $77 \%$ of the respondents were employed in the position of a ward nurse, and $11.5 \%$ in the position of a head nurse. The majority of participants were females $(75.5 \%)$ and married (68.5\%). Regarding the level of education, 95.6\% had a Bachelor's degree with 3 to 11 years of work experience (56.3\%). In terms of familiarity with computers, $66.5 \%$ were relatively good, $59 \%$ of nurses used computers more than once a day, and spent less than $1 \mathrm{~h}$ working with the HIS in each shift (59\%).

\section{Correlation between Demographic characteristics and nursing informatics competencies}

The correlation analysis results revealed no significant relationship between sex, marital status, level of education, work experience, frequency of computer usage, and interaction with the HIS and nurses' basic computer skills $(\mathrm{P}>0.05)$. However, there was a significant relationship between age, familiarity with computers, and nurses' basic computer skills $(\mathrm{P}<0.02)$. The results did not show any significant relationship between sex, age, level of education, work experience, and frequency of computer usage, and nursing informatics knowledge $(\mathrm{P}>0.05)$. Nevertheless, there was a significant relationship between marital status, familiarity with computers, and interaction with the HIS and nursing informatics knowledge $(\mathrm{P}<0.02)$. In the subscale of informatics skills, there was no significant relationship between sex, age, marital status, level of education, work experience, and frequency of computer usage and nursing informatics skills $(\mathrm{P}<0.05)$, while a significant relationship was observed between familiarity with computers, interaction with the HIS and nursing informatics skills $(\mathrm{P}<0.02)$.

\section{Validity of the questionnaire}

Table 2 shows CVI and CVR for each item. Among the questionnaire items, five items from the basic computer skills, 10 items from informatics knowledge, and 11 items from the informatics skills subscales were removed. Therefore, the number of items in the questionnaire was reduced to 48 (Additional file 1).

\section{Confirmatory factor analysis of the Questionnaire}

To determine which item belongs to each factor, the confirmatory factor analysis was used. The results showed a relatively good estimation in the fit of the first-order measurement model $\left(\chi^{2} / \mathrm{df}=1.59, \mathrm{GFI}=0.79, \mathrm{CFI}=0.99\right.$, $\mathrm{NFI}=0.97$, RMSEA $=0.055)$. It is worth mentioning that each subscale was separately analyzed through the confirmatory factor analysis using the LISREL, such that some items were removed to obtain a relatively appropriate measurement model (Fig. 1). Two items of basic computer skills and informatics knowledge and six items of informatics skills subscales were removed because the cut-off point was lower than $0.5\left(R^{2}<0.5\right)$.

Table 3 shows the discriminant validity and reliability for each subscale. Furthermore, to examine the fit of subscales, the subscales were analyzed along with all items in the first-order measurement model. Therefore, none of the items were removed (Fig. 1). Finally, the secondorder factor analysis was used to evaluate the effect of basic computer skills, informatics knowledge, and informatics skills on nursing informatics competencies and assess whether the entire subclass was put into the form as a concept (Fig. 2). It was observed that the subscale of informatics knowledge with the determining rate of 0.90 has the greatest explanatory effect among the subscales and informatics skills with the determining rate of 0.67 and basic computer skills with the determining rate of 0.60 were ranked second and third.

The second-order measurement model of fit indices showed that the three factors of basic computer skills, informatics knowledge, and informatics skills could explain the multidimensional construct of informatics competency and represent the dimensional accuracy in introducing a three-dimensional framework of informatics competency in the best way $\left(\mathrm{x}^{2} / \mathrm{df}=1.51, \mathrm{GFI}=0.80\right.$, $\mathrm{CFI}=0.99, \mathrm{NFI}=0.97$, RMSEA $=0.051$ ). Finally, the reliability assessment results from the test-retest method, using Spearman's rank correlation-coefficient $(\rho)$, showed that the nursing informatics competencies tool has the highest correlation in each subscale (more than 0.9).

\section{Discussion}

In the first part of this study, three areas of informatics competency were used as stated by Staggers et al. [14]. Content validity (CVI and CVR) of informatics competency items was assessed by experts with a 48 -item validated questionnaire. Staggers et al. [14] designed the classification of 3 -factor nursing informatics competencies with 37 items for beginner nurses and 32 items for experienced nurses including basic computer skills, informatics knowledge, and informatics skills. However, evaluation of the need for education at each specific level of nursing informatics competence was not possible [29].

Hunter et al. [9] made the list of nursing informatics competencies in three subscales including basic computer skills (51 items), information literacy ( 25 items), and clinical data management (9 items). In their study, 
Table 2 Validity in quantitative content analysis

\begin{tabular}{|c|c|c|c|c|c|c|}
\hline \multirow[t]{2}{*}{ Row } & \multirow[t]{2}{*}{ Basic computer skills } & \multicolumn{3}{|l|}{ CVI } & \multirow[t]{2}{*}{ CVR } & \multirow[t]{2}{*}{ Result } \\
\hline & & Simplicity & Clarity & Relevancy & & \\
\hline 1 & $\begin{array}{l}\text { Having basic computer skills (e.g. turning on and turning off the computer, printing, } \\
\text { documentation, using the mouse) }\end{array}$ & 0.75 & 0.75 & 0.83 & 1 & Confirmed \\
\hline 2 & Using windows operating system & 0.91 & 0.91 & 1 & 0.8 & Confirmed \\
\hline 3 & Being able to resolve common error reports & 0.75 & 0.7 & 0.75 & 0.8 & Confirmed \\
\hline 4 & $\begin{array}{l}\text { Using an antivirus software to scan } \\
\text { files, folders and drives }\end{array}$ & 1 & 0.9 & 0.7 & 0.6 & Confirmed \\
\hline 5 & Being able to back up computer files & 0.91 & 0.9 & 0.75 & 0.6 & Confirmed \\
\hline 6 & Operating peripheral devices such as printers and scanners & 0.83 & 0.83 & 0.75 & 0.6 & Confirmed \\
\hline 7 & Using spreadsheet applications such as Microsoft excel & 0.83 & 0.91 & 0.91 & 0.6 & Confirmed \\
\hline 8 & Using external storage devices such as CDs, DVDs and memory cards & 0.83 & 0.7 & 0.75 & 0.6 & Confirmed \\
\hline 9 & Changing the default printer from the installed printer list & 0.83 & 0.83 & 0.91 & 0.6 & Confirmed \\
\hline 10 & Using multimedia presentation devices & 0.33 & 0.25 & 0.41 & 0.33 & Rejected \\
\hline 11 & Using word processing software applications & 0.91 & 0.91 & 1 & 0.8 & Confirmed \\
\hline 12 & Having typing skills & 1 & 0.91 & 0.91 & 0.6 & Confirmed \\
\hline 13 & Using PowerPoint software application & 1 & 0.91 & 0.91 & 0.56 & Confirmed \\
\hline 14 & Using Access software application & 0.91 & 0.91 & 0.58 & -0.5 & Rejected \\
\hline 15 & Using the Internet & 0.91 & 0.91 & 0.83 & 0.77 & Confirmed \\
\hline 16 & Using search engines on the Internet & 1 & 1 & 0.91 & 0.8 & Confirmed \\
\hline 17 & $\begin{array}{l}\text { Using e-mails (e.g. sending mails, responding to mails, attaching files, forwarding mails } \\
\text { and deleting mails) }\end{array}$ & 0.91 & 1 & 0.91 & 0.6 & Confirmed \\
\hline 18 & Using the computer safely & 0.75 & 0.7 & 0.7 & 1 & Confirmed \\
\hline 19 & Using computerized self-learning equipment & 0.91 & 0.91 & 0.91 & 0.8 & Confirmed \\
\hline 20 & Installing windows operating system & 0.83 & 0.83 & 0.33 & -0.4 & Rejected \\
\hline 21 & $\begin{array}{l}\text { Using telecommunication devices such as modems or other devices to communicate } \\
\text { with other systems }\end{array}$ & 0.83 & 0.83 & 0.75 & -0.2 & Rejected \\
\hline \multirow[t]{3}{*}{22} & Using the techniques of encryption and access control & 0.58 & 0.41 & 0.36 & -0.33 & Rejected \\
\hline & \multirow[t]{2}{*}{ Informatics knowledge } & \multicolumn{3}{|l|}{ CVI } & \multirow[t]{2}{*}{ CVR } & \multirow[t]{2}{*}{ Result } \\
\hline & & Simplicity & Clarity & Relevancy & & \\
\hline 23 & Knowing the common computer terminology, e.g., bit, byte, RAM, ROM, etc & 0.91 & 0.91 & 0.58 & -0.2 & Rejected \\
\hline 24 & Knowing basic components of a computer's hardware system and their functions & 0.75 & 0.75 & 0.72 & 0.2 & Rejected \\
\hline 25 & Knowing the usage of file management function in computer operating system & 0.83 & 0.83 & 0.7 & 0.56 & Confirmed \\
\hline 26 & Knowing how to install software drivers for accessories & 0.75 & 0.75 & 0.41 & -0.2 & Rejected \\
\hline 27 & Describing information needed through key concepts and terms in nursing profession & 0.75 & 0.75 & 0.7 & 0.56 & Confirmed \\
\hline 28 & Determining the most appropriate methods for accessing information electronically & 0.72 & 0.75 & 0.7 & 0.6 & Confirmed \\
\hline 29 & Evaluating health information on the Internet using a structure critique format & 0.41 & 0.54 & 0.63 & 0.2 & Rejected \\
\hline 30 & Recognizing that there are human functions that cannot be performed by computers & 0.7 & 0.75 & 0.7 & 0.6 & Confirmed \\
\hline 31 & Knowing the probability of making mistakes by computer users & 0.81 & 0.75 & 0.81 & 0.6 & Confirmed \\
\hline 32 & $\begin{array}{l}\text { Knowing the importance of confidentiality and privacy when processing computerized } \\
\text { data and medical records }\end{array}$ & 0.72 & 0.75 & 0.9 & 0.6 & Confirmed \\
\hline 33 & $\begin{array}{l}\text { Applying the principles of data integrity, professional ethics and legal requirements for } \\
\text { patient confidentiality and data security }\end{array}$ & 0.72 & 0.72 & 0.91 & 0.6 & Confirmed \\
\hline 34 & $\begin{array}{l}\text { Understanding the essentials of information sources such as a variable form, different } \\
\text { characteristics, and various physical formats }\end{array}$ & 0.3 & 0.4 & 0.6 & -0.14 & Rejected \\
\hline 35 & Understanding and applying essential information-seeking concepts and practices & 0.83 & 0.7 & 0.75 & 0.6 & Confirmed \\
\hline 36 & Understanding the procedure of scholarly information & 0.66 & 0.58 & 0.83 & 0.2 & Rejected \\
\hline 37 & $\begin{array}{l}\text { Analyzing patient information needs, accesses technology resources etc. to meet the } \\
\text { needs and to evaluate effectiveness }\end{array}$ & 0.75 & 0.75 & 0.81 & 0.56 & Confirmed \\
\hline 38 & $\begin{array}{l}\text { Recognizing the need for continual learning informatics skills, applications, and knowl- } \\
\text { edge }\end{array}$ & 0.83 & 0.83 & 0.91 & 0.6 & Confirmed \\
\hline
\end{tabular}


Table 2 (continued)

\begin{tabular}{|c|c|c|c|c|c|c|}
\hline & \multirow[t]{2}{*}{ Informatics knowledge } & \multicolumn{3}{|l|}{ CVI } & \multirow[t]{2}{*}{ CVR } & \multirow[t]{2}{*}{ Result } \\
\hline & & Simplicity & Clarity & Relevancy & & \\
\hline 39 & $\begin{array}{l}\text { Recognizing that a computer program has limitations due to its design and computer } \\
\text { capacity }\end{array}$ & 0.75 & 0.75 & 0.7 & 0.6 & Confirmed \\
\hline 40 & $\begin{array}{l}\text { Recognizing that it takes time, persistent effort, and skill for computers to become effec- } \\
\text { tive tools }\end{array}$ & 0.91 & 0.83 & 0.91 & 0.6 & Confirmed \\
\hline 41 & Knowing about the laws regarding protecting personal information in computers & 0.83 & 0.91 & 0.91 & 1 & Confirmed \\
\hline 42 & $\begin{array}{l}\text { Recognizes that one does not have to be a computer programmer to use computers in } \\
\text { nursing effectively }\end{array}$ & 0.83 & 0.91 & 0.83 & 0 & Rejected \\
\hline 43 & $\begin{array}{l}\text { Recognizing that computers are not intelligent in themselves and must be programmed } \\
\text { based on users' needs }\end{array}$ & 1 & 1 & 0.83 & -0.2 & Rejected \\
\hline 44 & Describing patients' rights as pertaining to computerized information management & 0.54 & 0.41 & 0.9 & -0.6 & Rejected \\
\hline 45 & Recognizing the use and importance of nursing data for improving practice & 0.91 & 0.75 & 0.91 & 1 & Confirmed \\
\hline 46 & Recognizing when information and communicates are needed & 0.83 & 0.75 & 0.75 & 0.56 & Confirmed \\
\hline \multirow[t]{3}{*}{47} & $\begin{array}{l}\text { Recognizing the value of clinicians' involvement in the design, selection, implementa- } \\
\text { tion, and evaluation of applications and systems in healthcare }\end{array}$ & 0.66 & 0.66 & 0.66 & 0 & Rejected \\
\hline & \multirow[t]{2}{*}{ Informatics skills } & \multicolumn{3}{|l|}{ CVI } & \multirow[t]{2}{*}{ CVR } & \multirow[t]{2}{*}{ Result } \\
\hline & & Simplicity & Clarity & Relevancy & & \\
\hline 48 & Capturing data and information related to clinical care & 0.7 & 0.91 & 0.91 & 0.6 & Confirmed \\
\hline 49 & $\begin{array}{l}\text { Using wireless devices to locate and download resources for patient safety and quality } \\
\text { care }\end{array}$ & 0.66 & 0.75 & 0.58 & 0.4 & Rejected \\
\hline 50 & Using the HIS for nursing records & 1 & 1 & 1 & 0.8 & Confirmed \\
\hline 51 & Using the HIS to store, retrieve and transfer patient data & 1 & 1 & 1 & 0.77 & Confirmed \\
\hline 52 & Using applications for nursing diagnostic coding & 0.91 & 0.81 & 0.72 & 0.6 & Confirmed \\
\hline 53 & Extracting data from clinical data sets & 0.7 & 0.75 & 0.81 & 0.8 & Confirmed \\
\hline 54 & Accessing shared data sets & 0.75 & 0.7 & 0.9 & 0.6 & Confirmed \\
\hline 55 & $\begin{array}{l}\text { Participates in influencing the attitudes of other nurses toward computer use for nurs- } \\
\text { ing practice }\end{array}$ & 0.83 & 0.83 & 0.77 & 0.56 & Confirmed \\
\hline 56 & Using wireless devices to locate and download resources & 0.36 & 0.45 & 0.54 & -0.2 & Rejected \\
\hline 57 & $\begin{array}{l}\text { Accessing, entering and retrieves local data for patient care (e.g. using the HIS and CIS } \\
\text { for plans of care, assessment, intervention, notes and discharge planning }\end{array}$ & 0.75 & 0.75 & 0.9 & 0.6 & Confirmed \\
\hline 58 & Using database management programs to develop a simple databases or tables & 0.66 & 0.58 & 0.63 & 0 & Rejected \\
\hline 59 & Using an application to plan patient care including discharge planning & 0.83 & 0.9 & 0.83 & 0.6 & Confirmed \\
\hline 60 & Using database software programs to construct nursing databases & 0.66 & 0.72 & 0.33 & 0.2 & Rejected \\
\hline 61 & Assessing health information accuracy online & 0.54 & 0.63 & 0.72 & 0.2 & Rejected \\
\hline 62 & Applying patient tele-monitoring systems & 0.91 & 0.75 & 0.75 & 0.11 & Rejected \\
\hline 63 & Selecting system or application software programs & 0.66 & 0.5 & 0.54 & 0.33 & Rejected \\
\hline 64 & Participating in selection, design, implementation and evaluation of systems & 0.83 & 0.75 & 0.7 & 0.56 & Confirmed \\
\hline 65 & Teaching users and clients of nursing systems & 0.83 & 0.7 & 0.77 & 0.6 & Confirmed \\
\hline 66 & Correcting some of the defects observed in working with systems & 0.83 & 0.91 & 0.7 & 0.8 & Confirmed \\
\hline 67 & Applying information management technology for patient education & 0.91 & 1 & 0.91 & 0.8 & Confirmed \\
\hline 68 & Using related social networks on the Internet & 0.91 & 0.72 & 0.58 & 0 & Rejected \\
\hline 69 & Using multimedia files for learning & 0.75 & 0.91 & 0.83 & 0.56 & Confirmed \\
\hline 70 & Being capable of creating and managing blogs or websites & 0.91 & 0.91 & 0.58 & -0.11 & Rejected \\
\hline 71 & Using Endnote software application & 0.91 & 0.83 & 0.5 & 0 & Rejected \\
\hline 72 & $\begin{array}{l}\text { Using statistical software programs such as SPSS and other software programs for nurs- } \\
\text { ing information analysis }\end{array}$ & 0.91 & 1 & 0.58 & 0.2 & Rejected \\
\hline 73 & Using library information and downloading nursing articles & 1 & 1 & 0.75 & 0.8 & Confirmed \\
\hline 74 & Using search engines & 1 & 0.91 & 0.83 & 0.8 & Confirmeo \\
\hline
\end{tabular}

CVI: Content Validity Index; CVR: Content Validity Ratio; CD: Compact Disc; DVD: Digital Versatile Disc; RAM: Random Access Memory; ROM: Read-Only Memory; HIS: Hospital Information System; CIS: Clinical Information System; SPSS: Statistical Package for the Social Sciences 


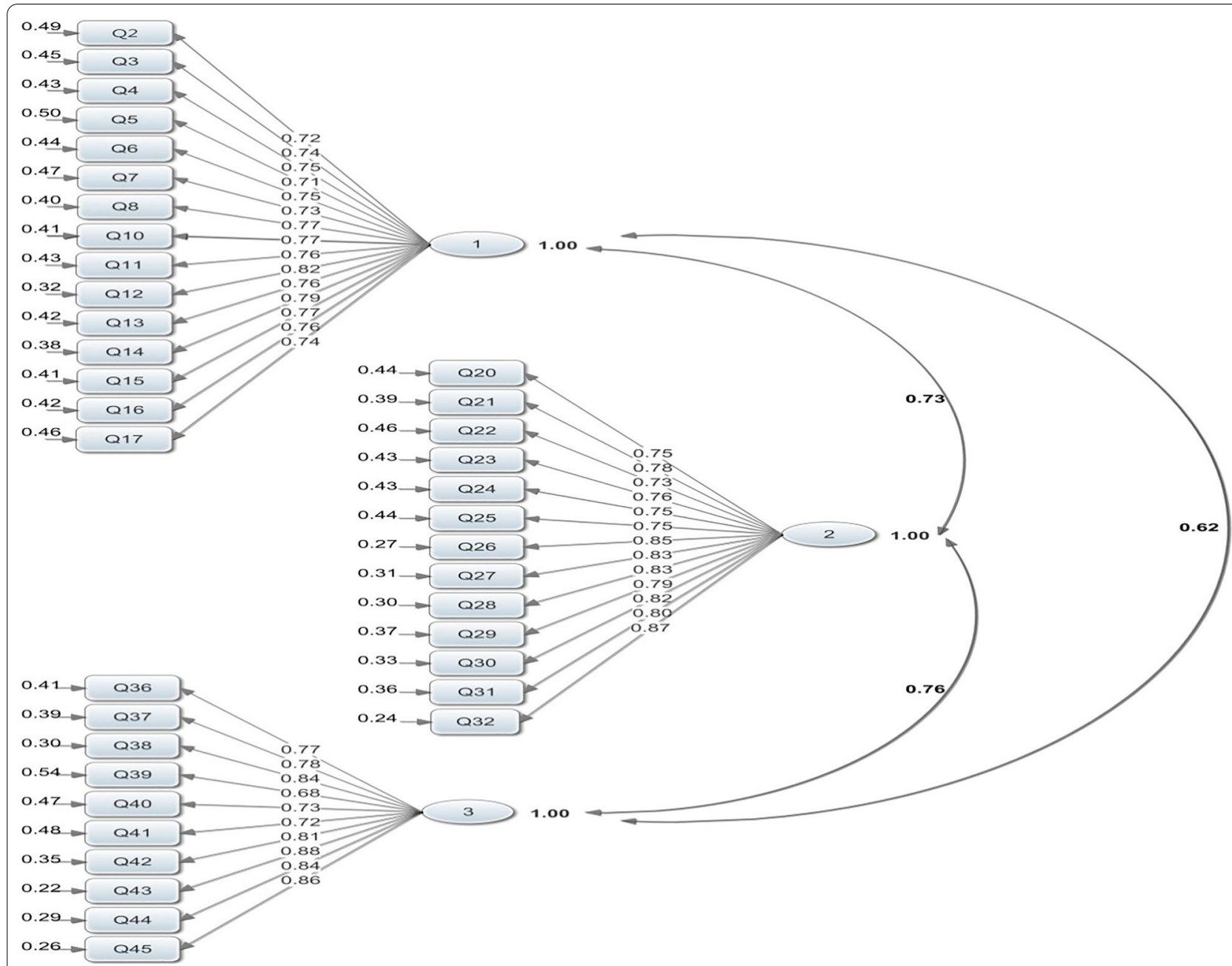

Fig. 1 The three-factor structure of first order confirmatory factor analysis of nursing informatics competency. Chi-square $=983.61, \mathrm{df}=616$, $p$-value $=0.00001$, RMSEA $=0.055$

while basic computer skills were listed in detail, items such as PowerPoint familiarity, Excel familiarity, working with accessories, and typing skills were not listed. In conclusion, it seems that the designed tools in the present study are more complete and more comprehensive in the field of basic computer skills and all the necessary dimensions in this context have been taken into consideration.

Hart [30] performed a three-round Delphi study to determine core informatics competencies for generic nurse managers resulting in a list of 49 core informatics competencies that were categorized into three groups including computer skills, informatics knowledge, and informatics skills. Nonetheless, the list does not mention the practical, research, and educational competencies [29]. Chang et al. [31] conducted a Delphi technique to identify informatics competencies required for nurses in Taiwan. The results showed that 318 informatics competencies for nurses had $97.8 \%$ consensus with the results of the study conducted by Staggers et al. [14].

Hwang et al. [32] designed a specific classification for nursing informatics competencies in their study. They classified parts of basic computer skills in the form of informatics knowledge and its original classification; they introduced computer trends structure as one of the three factors affecting nursing informatics competencies in Taiwan whose significance was more than basic computer skills. The difference between the items of these two studies is due to the variety in the classification of nursing informatics competencies structures. Also, the knowledge of using the HIS as an important variable is considered in the informatics knowledge structure in the study conducted by Hwang et al. [32]. This variable was not considered in the present study since it is only the skill of using it that has been classified in the informatics skill structure. This research is the only study assessing 
Table 3 Reliability and construct validity

\begin{tabular}{|c|c|c|c|c|c|c|}
\hline Items & Subscale & Factor loading & $\mathrm{R}^{2}$ & T-value & CR & AVE \\
\hline & Basic computer skills & & & & 0.56 & 0.95 \\
\hline 1 & Using windows operating system & 0.73 & 0.53 & 11.56 & & \\
\hline 2 & Being able to resolve common error reports on the computer & 0.76 & 0.57 & 12.21 & & \\
\hline 3 & Using the antivirus software program to scan files, folders and drives & 0.76 & 0.58 & 12.34 & & \\
\hline 4 & Being capable of backing up computer files & 0.73 & 0.53 & 11.63 & & \\
\hline 5 & Operating computer accessories such as printers and scanners & 0.76 & 0.58 & 12.30 & & \\
\hline 6 & Using spreadsheet applications such as Microsoft Excel & 0.75 & 0.56 & 12 & & \\
\hline 7 & Using external storage devices such as CD-ROMs, DVD ROMs, memory disks etc & 0.79 & 0.63 & 13.11 & & \\
\hline 8 & Using word processing software programs & 0.74 & 0.55 & 11.90 & & \\
\hline 9 & Having typing skills & 0.73 & 0.54 & 11.71 & & \\
\hline 10 & Using PowerPoint software application & 0.81 & 0.65 & 13.54 & & \\
\hline 11 & Using the Internet & 0.70 & 0.50 & 10.95 & & \\
\hline 12 & Using search engines on the Internet & 0.76 & 0.57 & 12.22 & & \\
\hline 13 & $\begin{array}{l}\text { Using e-mails (e.g. sending mails, responding to mails, attaching files, forwarding mails and delet- } \\
\text { ing mails) }\end{array}$ & 0.75 & 0.56 & 11.98 & & \\
\hline 14 & Using computer-based technologies safely & 0.77 & 0.60 & 12.62 & & \\
\hline \multirow[t]{2}{*}{15} & Using computerized self-learning equipment & 0.70 & 0.50 & 10.91 & & \\
\hline & Informatics knowledge & & & & 0.95 & 0.65 \\
\hline 16 & Determining the most appropriate methods for accessing information electronically & 0.71 & 0.51 & 11.37 & & \\
\hline 17 & Recognizing that there are human functions that cannot be performed by computers & 0.78 & 0.61 & 12.89 & & \\
\hline 18 & Knowing the probability of making mistakes by computers & 0.73 & 0.54 & 11.78 & & \\
\hline 19 & $\begin{array}{l}\text { Knowing the importance of confidentiality and privacy when processing computerized data and } \\
\text { medical records }\end{array}$ & 0.76 & 0.57 & 12.28 & & \\
\hline 20 & $\begin{array}{l}\text { Applying the principles of data integrity, professional ethics and legal requirements for patient } \\
\text { confidentiality and data security }\end{array}$ & 0.77 & 0.60 & 12.61 & & \\
\hline 21 & Understanding and applying essential information-seeking concepts and practices & 0.74 & 0.54 & 11.83 & & \\
\hline 22 & $\begin{array}{l}\text { Analyzing patient information needs and accessing technology resources to meet needs and } \\
\text { evaluate effectiveness }\end{array}$ & 0.79 & 0.63 & 13.11 & & \\
\hline 23 & Recognizing the need for continual learning of informatics skills, applications, and knowledge & 0.85 & 0.72 & 14.62 & & \\
\hline 24 & Recognizing that a computer program has limitations due to its design and computer capacity & 0.82 & 0.68 & 13.97 & & \\
\hline 25 & Recognizing that it takes time, persistent effort, and skill for computers to become effective tools & 0.81 & 0.65 & 13.55 & & \\
\hline 26 & Knowing about the laws regarding protecting personal information in computers & 0.81 & 0.66 & 13.63 & & \\
\hline 27 & Recognizing the use and importance of nursing data for improving practice & 0.83 & 0.69 & 14.05 & & \\
\hline \multirow[t]{2}{*}{28} & Recognizing when information and communicates are needed & 0.88 & 0.77 & 15.43 & & \\
\hline & Informatics skills & & & & 0.94 & 0.61 \\
\hline 29 & Using applications for diagnostic coding & 0.71 & 0.50 & 11.10 & & \\
\hline 30 & Extracting data from clinical data sets & 0.75 & 0.57 & 12.07 & & \\
\hline 31 & Accesses shared data sets & 0.78 & 0.61 & 12.59 & & \\
\hline 32 & Participates in influencing the attitudes of other nurses toward computer use for nursing practice & 0.71 & 0.50 & 11.10 & & \\
\hline 33 & $\begin{array}{l}\text { Accessing, entering and retrieves local data for patient care (e.g. using the HIS and CIS for plans of } \\
\text { care, assessment, intervention, notes and discharge planning }\end{array}$ & 0.76 & 0.58 & 12.38 & & \\
\hline 34 & Using an application to plan care for patient including discharge planning & 0.77 & 0.59 & 12.52 & & \\
\hline 35 & Participating in selection, design, implementation and evaluation of systems & 0.81 & 0.65 & 13.27 & & \\
\hline 36 & Teaching users and clients of nursing systems & 0.87 & 0.76 & 15.15 & & \\
\hline 37 & Correcting some of the defects observed in working with systems & 0.85 & 0.73 & 14.46 & & \\
\hline 38 & Applying information management technology for patient education & 0.84 & 0.70 & 14.09 & & \\
\hline
\end{tabular}

CR: Composite Reliability; R²: R-Squared; AVE: Average Variance Extracted; DVD: Digital Versatile Disc; ROM: Read-Only Memory; HIS: Hospital Information System; CIS: Clinical Information System; 


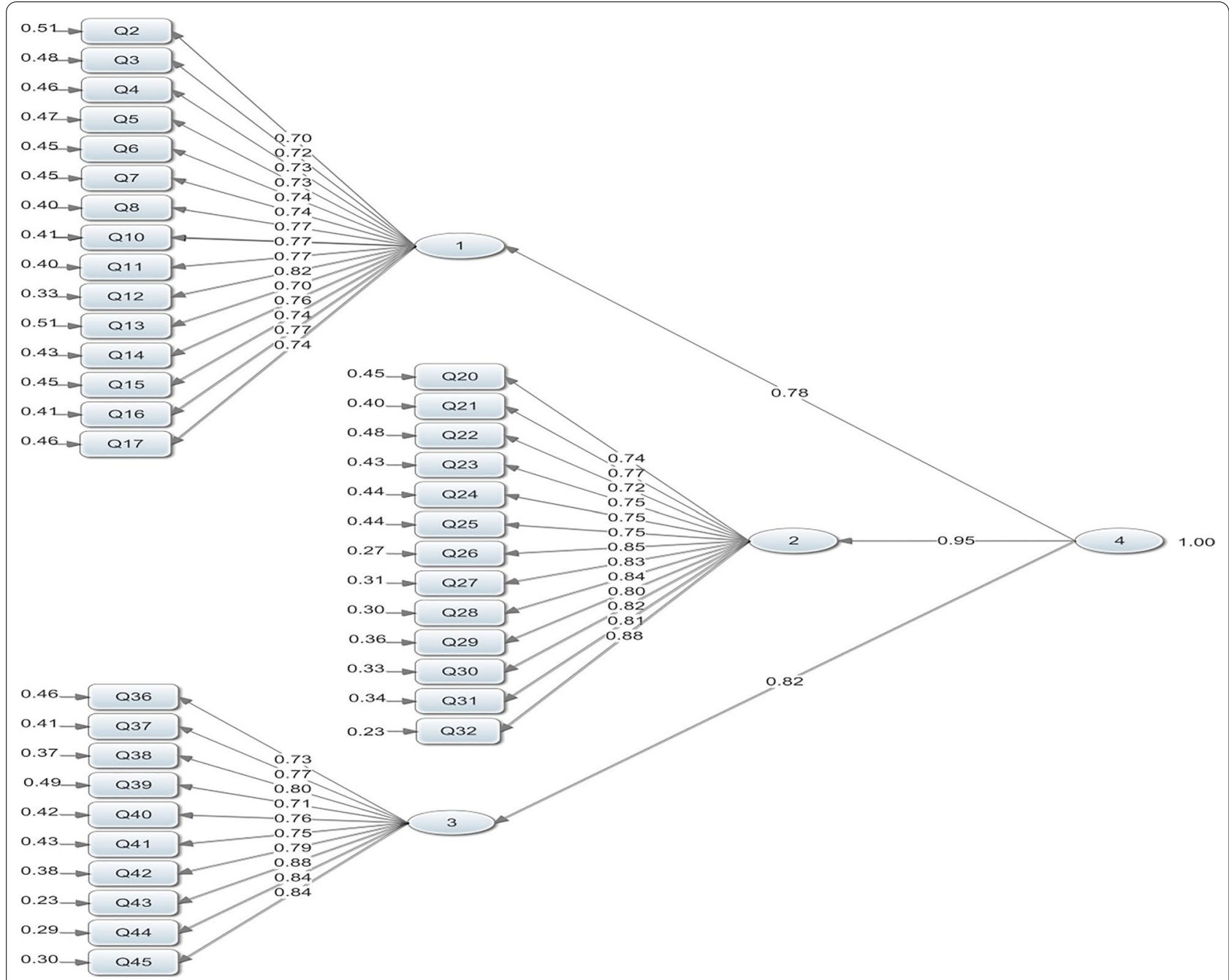

Fig. 2 The three-factor structure of second order confirmatory factor analysis of nursing informatics competency. Chi-square $=931.57, \mathrm{df}=613$, $p$-value $=0.00001$, RMSEA $=0.051$

nursing informatics competence confirming the threefactor structure including basic computer skills, informatics knowledge, and informatics skills with regard to the suitability of various indicators of structural equation modeling.

Westra et al. [33] introduced 92 items related to nursing informatics competencies based on the work of Staggers et al. [14], including 24 items related to computer skills, 40 items related to informatics knowledge, and 28 items related to informatics skills. This list is the same as the one provided by Hart [30] in providing specific qualifications of access to data, communication, systems, data dissemination, and training. This list is useful for determining individuals' specific competence while it does not allow the evaluation of the level of competence at a particular level of practice. Westra's list emphasizes the knowledge and skills of informatics in the role of nurses' leadership for planning, supporting, directing, and evaluating information initiatives beyond the practical skills of nurses for action [29].

Lenburg [34] provided an 8-core practice list of essential competencies for nursing including assessment and intervention skills, communication, critical thinking, human caring, teaching, management, leadership, and knowledge integration skills. In competence of communication skills, the sub-skill of computing, it is discussed in which only customer communication, search for resources, and specialized responsibility were provided. In this list, informatics was not presented as a core competence of nursing whereas it is of great importance because of the integration of technology and information communication in contemporary nursing. The difference between Lenburg's study and the present one is that, in the present study, informatics competencies emphasize 
computer skills and informatics skills when discussing nursing practices.

In another study administered by Cronenwett et al. [35], a list of recommended qualifications was required for all nurses to provide safe care to patients. In the classification provided, at the level of informatics competencies, only 3 subjects including knowledge, skill, and attitude were mentioned. The list is generally a useful tool for identifying current nurses' competencies; however, the informatics section is inadequate in identifying vital concepts of nursing competencies. This study lists the qualifications while it does not show the depth of the skills and the level of training required at each particular level [29].

TIGER research [36] presented a list of essential informatics competencies for experienced nurses including levels of basic computer competence, information literacy, and information management. At the level of basic computer competence, varied items concerning hardware and software intelligence, various forms of electronic communication, recognition of safety and operating systems, using the Internet, and many other items were listed. There are also several competencies in the information literacy and information management area which cannot be evaluated using this list [29]. Integrated informatics was considered to improve education, provide care, and practical measures for nurses [37]. TIGER's tool was developed for all nurses without specification for level of practice and included 281 competencies. Nevertheless, the use of information technology in the field of health in this country is at an early stage and nursing experts have not presently considered many of the competencies as important and in practice, there is no need to teach them to all nurses. Therefore, nursing informatics can be created in countries that do not have this field, and higher-level activities in the field of clinical health information systems can be expected from them.

In the study by Hubner et al. [38], a broad list of core competencies for nurses was identified based on five nursing domains including clinical nursing, quality management, inter-professional coordination, nursing management, and information technology management. They provided six core informatics competencies in each of the five nursing areas. However, this tool was not carefully developed as the tool demonstrates core competencies, such as nurses' documentation and information knowledge management, without identifying the competency items under each core competency [39].

Kaminski [40] also introduced a framework determining a specific classification of nursing skills. This list includes a set of competencies required for different levels of nursing. The tool is capable of assessing the presence or absence of nursing skills while it does not show the degree of nursing mastery to the details of the aforementioned skills [29]. In the instrument presented in this study, nursing competence was generally evaluated since nurses were not assessed in terms of their levels in the working field.

The differences between the present study and other studies are due to the differences in concept definitions, the type and level of technology used and the kind of competence that is required. Competencies such as the use of decision support systems, database management systems, database software, remote patient monitoring systems, effective care design tools and appropriate technology to collect patient-related data were considered essential for nurses in Stagger's study. Since in many developing countries, hospital information systems and applications in the field of public health, especially in nursing care, are in the early and experimental stages and have not reached the implementation stage, these competencies were not agreed upon and approved by the experts in this study. The competencies agreed in this area are mostly related to the basic and primary principles of working with computers.

However, the results of this study in terms of construct validity and confirmatory factor analysis as assessed through the 3-factor structure of the Persian version of the nursing informatics competencies questionnaire were different from the results reported in other studies [11, $41,42]$. The reasons behind the difference in the number of factors can be linked to different statistical methods such as exploratory functional analysis concerned with the derivation and determination of the relationships between the factors.

One of the findings of the present study is the relationship between the 3-factor model of nursing informatics competencies and their subscales (Figs. 1, 2). The strongest relationship was observed between informatics knowledge (0.95) and informatics competencies while the weakest relationship was observed between basic computer skills (0.78) and informatics qualifications. In analyzing these results, it is noteworthy to mention that informatics knowledge had a stronger impact on informatics competencies than the other two subscales. Moreover, enhancing nursing informatics knowledge plays a greater role in increasing informatics competencies. In the study conducted by Yang et al. [11], sufficient knowledge regarding technology use significantly increased nurses informatics competencies.

Nevertheless, in a study conducted by Arzu Akman et al. [41], the studied participants had no knowledge of nursing informatics. However, $2.86 \%$ of them stated that nursing informatics courses must be included in the nursing curriculum. The computer-based nursing curricula should be dynamically based on the regional needs 
and adaptations to new professional attitudes to assure the possibility of training the nurses in order to guarantee an adequate level of expertise concerning informatics. The result of this study showed that the questionnaire was reliable, with the minimum reliability coefficient being related to test-retest of informatics skills subscale $(0.95)$ and the highest reliability coefficient being related to basic computer skills subscales (0.99). In the study done by Akman et al. [41], the reliability of the designed tools was proper. The results of the present study showed that participants' level of informatics capabilities was medium. In other studies, nursing informatics skills are have been shown to be at an intermediate level $[11,42$, 43].

\section{Implications for practice and future research}

The presented tool can be used to develop educational strategies for nursing students in the field of informatics and to prepare them in the rich environment of information technology in the healthcare environment of developing countries. Therefore, the Faculty members of Nursing and Midwifery and the Education Deputy of Ministry of Health, Treatment, and Medical Education can benefit from the results of this study. Future nurses cannot be well-prepared to confront challenges in the various professional fields without the acquisition of technical skills. Therefore, nurses should be able to use data, information, knowledge, and technologies properly to improve nursing care. In this regard, nursing informatics can play a significant role in the areas of education, healthcare provision, research, and management and be used for preservation and storage of clinical care and the extension of research studies that are directly related to the quality of patient healthcare.

\section{Conclusion}

Since nurses are regarded as the largest part of the healthcare workforce and the major users of clinical information systems, nursing informatics competencies are important for the successful use of clinical information systems and improving patient safety in computerized environments. Therefore, the nursing profession needs to promote the acceptance and usage of information technology to empower nursing informatics competencies. For this purpose, the informatics competencies approved in the present questionnaire can be helpful for educational administrators in order to train nurses and include a special course for nursing informatics in the educational curriculum. This questionnaire can also be useful in periodically evaluating the level of informatics competencies of working nurses and nursing students in different communities.

\section{Supplementary information}

The online version contains supplementary material available at https://doi. org/10.1186/s12911-021-01405-0.

Additional file 1. English Questionnaire.

\section{Abbreviations}

LISREL: Linear structural relations; ICT: Information and Communications Technology; EHR: Electronic Health Records; HIS: Hospital Information System; CVI: Content Validity Index; CVR: Content Validity Ratio; AVE: Average Variance Extracted; RMSEA: Root Mean Square Error of Approximation; CFA: Confirmatory Factor Analysis; GFI: Goodness of Fit Index; NFI: Normed fit index.

\section{Acknowledgements}

The authors would like to thank the nurses who participated in the study.

\section{Authors' contributions}

Conception and design of study (MF, HM), Development of materials (MF, HM), Data collection (SS), Data analysis and interpretation (HA), Drafting the article (MF, SS, RSh), Revising article critically for important intellectual content (MF, $\mathrm{RSh}$ ), Final approval of the version to be published (MF, HM, RSh). All authors read and approved the final manuscript.

\section{Funding}

This study was supported by a grant from Kashan University of Medical Sciences Research Council (Number: 93089) and did not receive any specific grant from funding agencies in the public, commercial, or not-for-profit sectors.

\section{Availability of data and materials}

The datasets used and/or analysed during the current study available from the corresponding author on reasonable request.

\section{Ethics approval and consent to participate}

Before conducting the research, verbal consent was obtained from all participants. They were informed that they could withdraw from the study at any time. All questionnaires were anonymous and the participants were assured of the confidentiality of their information. The study was performed in compliance with the World Medical Association Declaration of Helsinki on Ethical Principles for Medical Research Involving Human Subjects, and Ethical approval was elicited from the Ethical Committee at the Iran University of Medical Sciences.

\section{Consent for publication}

Not applicable.

\section{Competing interests}

The authors declare that they have no competing interests.

\section{Author details}

${ }^{1}$ Health Information Management Research Center, Department of Health Information Management and Technology, School of Allied Health Professions, Kashan University of Medical Sciences, Pezeshk Blvd, 5th of Qotbe Ravandi Blvd - Pardis Daneshgah, Kashan, Islamic Republic of Iran. ${ }^{2}$ Research Centre for Health-Related Social Determinates, Department of Health Education and Promotion, Ahvaz Jundishapur University of Medical Sciences, Ahvaz, Islamic Republic of Iran. ${ }^{3}$ Department of Biostatistics and Epidemiology, School of Health, Kashan University of Medical Sciences, Kashan, Islamic Republic of Iran.

Received: 16 April 2020 Accepted: 21 January 2021

Published online: 02 February 2021

References

1. Safdari R, Azadmanjir Z. Solutions and strategies for nursing informatics development. Int J Nurs Health Sci. 2014;1(1):4-12. 
2. Ball MJ, Hannah KJ, Newbold SK: What is informatics and what does it mean for nursing? In: Health Informatics. New York: Springer; 1995: 71-76. https://doi.org/10.1007/978-1-4757-2428-8_6

3. Darvish A, Bahramnezhad F, Keyhanian S, Navidhamidi M. The role of nursing informatics on promoting quality of health care and the need for appropriate education. Global J Health Sci. 2014;6(6):11-8. https://doi. org/10.5539/gjhs.v6n6p11.

4. International Medical Informatics Association: The nursing informatics special interest group-definition. https://www.amia.org/programs/worki ng-groups/nursing-informatics (2009).

5. Healthcare Information and Management Systems Society (HIMSS): Nursing Informatics Workforce Survey. https://www.himss.org/resources/ himss-nursing-informatics-workforce-survey (2020). Accessed 20 Aug 2020.

6. Jensen R. Guedes EdS, Leite MMJ: Informatics competencies essential to decision making in nursing management. Revista da Escola de Enfermagem da USP. 2016;50(1):109-17. https://doi.org/10.1590/S0080-62342 0160000100015.

7. Garside JR, Nhemachena JZ. A concept analysis of competence and its transition in nursing. Nurse Educ Today. 2013;33(5):541-5. https://doi. org/10.1016/j.nedt.2011.12.007.

8. Donilon DM: Nurses Perceptions of their Competence in Managing Patient Situations in Acute Care. 2013. https://digitalcommons.uri.edu/ oa_diss/13.

9. Hunter KM, McGonigle DM, Hebda TL. TIGER-based measurement of nursing informatics competencies: the development and implementation of an online tool for self-assessment. J Nurs Educ Pract. 2013;3(12):70-80. https://doi.org/10.5430/jnep.v3n12p70.

10. Sunmoo Y, Po-Yin Y. Psychometric properties of the self-assessment of nursing informatics competencies scale. Stud Health Technol Inf. 2009:146:546-50.

11. Yang L, Cui D, Zhu X, Zhao Q, Xiao N, Shen X: Perspectives from nurse managers on informatics competencies. The Scientific World Journal 2014, 2014. doi: https://doi.org/10.1155/2014/391714.

12. Peterson HE, Gerdin-Jelger U: Preparing Nurses for Using Information Systems: Natl Leagu; 1988.

13. Grobe S. Nursing informatics competencies for nurse educators and researchers. NLN Publ. 1988;14-2234:25-40.

14. Staggers N, Gassert CA, Curran C. A Delphi study to determine informatics competencies for nurses at four levels of practice. Nurs Res. 2002;51(6):383-90.

15. Staggers N, Gassert CA, Skiba DJ. Health professionals' views of informatics education: findings from the AMIA 1999 spring conference. J Am Med Inform Assoc. 2000;7(6):550-8.

16. Staggers N, Gassert CA, Curran C. Informatics competencies for nurses at four levels of practice. J Nurs Educ. 2001;40(7):303-16.

17. Jouparinejad S, Foroughameri G, Khajouei R, Farokhzadian J. Improving the informatics competency of critical care nurses: results of an interventional study in the southeast of Iran. BMC Med Inform Decis Mak. 2020;20(1):1-12. https://doi.org/10.1186/s12911-020-01244-5.

18. Rahman AA: Development of a nursing informatics competency assessment tool (NICAT). 2015

19. Polit DF, Beck CT, Owen SV. Is the CVI an acceptable indicator of content validity? Appraisal and recommendations. Res Nurs Health. 2007:30(4):459-67.

20. Kline RB: Principles and practice of structural equation modeling: Guilford publications; 2015

21. Lawshe $\mathrm{CH}$. A quantitative approach to content validity. Pers Psychol. 1975;28(4):563-75.

22. Prudon P: Confirmatory Factor Analysis as a Tool in Research Using Questionnaires: A Critique 1, 2. Comprehensive Psychology 2015, 4:03. CP. 04.10
23. Schreiber JB, Nora A, Stage FK, Barlow EA, King J. Reporting structural equation modeling and confirmatory factor analysis results: a review. J Educ Res. 2006;99(6):323-38.

24. Hair JF, Anderson RE, Babin BJ, Black WC: Multivariate data analysis: A global perspective, vol. 7: Pearson Upper Saddle River, NJ; 2010.

25. Peterson RA, Kim Y. On the relationship between coefficient alpha and composite reliability. In.: American Psychological Association; 2013.

26. Bertea P, Zait A. Methods for testing discriminant validity. Manag Market Craiova. 2011;2:217-24.

27. Hulland J: Use of partial least squares (PLS) in strategic management research: A review of four recent studies. Strat Manag J 1999:195-204.

28. Fornell C, Larcker DF: Structural equation models with unobservable variables and measurement error: algebra and statistics. J Mark Res 1981:382-388.

29. Greer H: Nursing informatics competencies: implications for safe and effective practice. 2012

30. Hart MD. A Delphi study to determine baseline informatics competencies for nurse managers. Comput Inf Nurs. 2010;28(6):364-70.

31. Chang J, Poynton MR, Gassert CA, Staggers N. Nursing informatics competencies required of nurses in Taiwan. Int J Med Informatics. 2011;80(5):332-40.

32. Hwang $\mathrm{H}-\mathrm{g}$, Chen R-f, Chang $\mathrm{L}-\mathrm{H}$, Hsiao J-L: A study of the informatics literacy of clinical nurses in Taiwan. CIN 2008, 26(5):290-299.

33. Westra BL, Delaney CW: Informatics competencies for nursing and healthcare leaders. In: AMIA Annual Symposium Proceedings: 2008 : American Medical Informatics Association; 2008: 804.

34. Lenburg C. The framework, concepts and methods of the competency outcomes and performance assessment (COPA) model. Online J Issues Nurs. 1999:4(2):1-12.

35. Cronenwett L, Sherwood G, Barnsteiner J, Disch J, Johnson J, Mitchell P. Sullivan DT, Warren J. Quality and safety education for nurses. Nurs Outlook. 2009;55(3):122-31.

36. Fung KYM: Utilizing TIGER Competencies to Improve Informatics Practice. 2016

37. Gugerty B, Delaney C, DuLong D: The TIGER initiative, informatics competencies for every practicing nurse: recommendations from the TIGER collaborative. Technology Informatics Guiding Education Reform. 1-33. In.; 2012.

38. Hubner U, Shaw T, Thye J, Egbert N, Marin H, Ball M. Towards an International Framework for Recommendations of Core Competencies in Nursing and Inter-Professional Informatics: The TIGER Competency Synthesis Project. Stud Health Technol Inform. 2016;228:655-9.

39. Ali RA, Benjamin K, Munir S, Ahmed N. A review of informatics competencies tools for nurses and nurse managers. Can J Nurs Inf. 2018;13(1):1.

40. Kaminski J: Nursing Informatics Competencies: Self-Assessment. In.: Retrieved from http://nursing-informatics.com/niassess/index.html. 2012.

41. Arzu Akman RN, M, Tekindal MA, . Psychometric properties and reliability of the Turkish version of the technology attitudes survey and nursing students' attitudes toward technology. Int J Caring Sci. 2014;7(2):415.

42. Fetter MS. Graduating nurses' self-evaluation of information technology competencies. J Nurs Educ. 2009:48(2):86-90.

43. MCDOWELL DE, Ma X: Computer literacy in baccalaureate nursing students during the last 8 years. CIN: Computers, Informatics, Nursing 2007, 25(1):30-36.

\section{Publisher's Note}

Springer Nature remains neutral with regard to jurisdictional claims in published maps and institutional affiliations. 